\title{
A discretized model for enzymatic hydrolysis of cellulose in a fed-batch process
}

Petri Tervasmäki*1, Ville Sotaniemi ${ }^{1}$, Jani Kangas ${ }^{1}$, Sanna Taskila ${ }^{1}$, Heikki Ojamo ${ }^{2}$, Juha Tanskanen ${ }^{1}$

${ }^{1}$ Chemical Process Engineering, Faculty of Technology, University of Oulu, P.O.Box 4300, FI-90014 Oulun yliopisto, Finland

2 Department of Biotechnology and Chemical Technology, School of Chemical Technology, Aalto University, P.O. Box 16100, 00076, Aalto, Finland

*Corresponding author, petri.tervasmaki@oulu.fi, +358 405474973

\begin{abstract}
In the enzymatic hydrolysis of cellulose, several phenomena have been proposed to cause a decrease in the reaction rate with increasing conversion. The importance of each phenomenon is difficult to distinguish from batch hydrolysis data. Thus, kinetic models for the enzymatic hydrolysis of cellulose often suffer from poor parameter identifiability. This work presents a model that is applicable to fed-batch hydrolysis by discretizing the substrate based on the feeding time. Different scenarios are tested to explain the observed decrease in reaction rate with increasing conversion, and comprehensive assessment of the parameter sensitivities is carried out. The proposed model performed well in the broad range of experimental conditions used in this study and when compared to literature data. Furthermore, the use of data from fed-batch experiments and discretization of the model substrate to populations was found to be very informative when assessing the importance of the rate-decreasing phenomena in the model.
\end{abstract}

\section{Keywords}

cellulose; enzymatic hydrolysis; kinetic model; fed-batch; 


\section{Nomenclature}

\begin{tabular}{|c|c|}
\hline$D$ & Dilution rate $\left(h^{-1}\right)$ \\
\hline$E_{\mathrm{A}}$ & Adsorbed enzyme concentration $\left(\mathrm{g}_{\mathrm{p}} \mathrm{l}^{-1}\right)$ \\
\hline$E_{\mathrm{f}}$ & Free enzyme concentration $\left(\mathrm{g}_{\mathrm{p}} \mathrm{I}^{-1}\right)$ \\
\hline$E_{\text {tot }}$ & Total amount of enzyme $\left(\mathrm{g}_{\mathrm{p}} \mathrm{l}^{-1}\right)$ \\
\hline$E_{\max }$ & Enzyme adsorption capacity in Langmuir model $\left(\mathrm{g}_{\mathrm{p}} \mathrm{g}_{\mathrm{cel}} \mathrm{I}^{-1}\right)$ \\
\hline$E_{\max 0}$ & Enzyme adsorption capacity of unconverted substrate $\left(g_{p} g_{c e l}{ }^{-1}\right)$ \\
\hline$F$ & Feed rate of substrate $\left(g_{\text {cel }} h^{-1}\right)$ \\
\hline G & Glucose concentration in the slurry $\left(\mathrm{gglu}_{\mathrm{gl}} \mathrm{I}^{-1}\right)$ \\
\hline$G_{\text {liq }}$ & Glucose concentration in liquid phase $\left(\mathrm{g}_{\mathrm{glu}}{ }^{\mathrm{I}^{-1}}\right)$ \\
\hline$i$ & Index of the substrate population in fed-batch mode \\
\hline$k_{\text {Ads }}$ & Adsorption rate constant $\left(\mathrm{gg}_{\mathrm{p}}^{-1} \mathrm{~h}^{-1}\right)$ \\
\hline$k_{\max }$ & Reaction rate constant $\left(\mathrm{g}_{\text {cel }} \mathrm{g}_{\mathrm{p}}^{-1} \mathrm{~h}^{-1}\right)$ \\
\hline$k_{\text {Emax }}$ & Adjustable parameter \\
\hline$K_{\mathrm{L}}$ & Equilibrium constant $\left(\mathrm{g}_{\mathrm{p}} \mathrm{I}^{-1}\right)$ \\
\hline$K_{\mathrm{I}, \mathrm{G}}$ & Inhibition constant for glucose $\left(\left.\mathrm{g}_{\text {glu }}\right|^{-1}\right)$ \\
\hline$M$ & Molecular weight $\left(\mathrm{g} \mathrm{mol}^{-1}\right)$ \\
\hline$n_{\text {Emax }}$ & Adjustable parameter (-) \\
\hline$n_{\exp }$ & Number of experiments used in parameter estimation \\
\hline$n_{\mathrm{m}}$ & Number of measurements in a single experimental run \\
\hline$n_{0}$ & Adjustable parameter (-) \\
\hline$q$ & Adjustable parameter $\left(\left.\mathrm{g}_{\mathrm{cel}}\right|^{-1}\right)$ \\
\hline$r$ & Reaction rate of cellulose $\left(\mathrm{g}_{\text {cel }} l^{-1} \mathrm{~h}^{-1}\right)$ \\
\hline$S_{c}$ & Concentration of cellulose $\left(\mathrm{g}_{\text {cel }}{ }^{-1}\right)$ \\
\hline $\mathrm{S}_{\mathrm{c}, 0}$ & Initial cellulose concentration $\left(\mathrm{g}_{\text {cel }} \mathrm{I}^{-1}\right)$ \\
\hline$S_{c, A c c}$ & Total mass of added cellulose $\left(g_{\text {cel }}\right)$ \\
\hline$S_{s}$ & Concentration of total solids $\left(\left.\mathrm{g}_{\text {sol }}\right|^{-1}\right)$ \\
\hline$t$ & Time (h) \\
\hline$V$ & Volume (I) \\
\hline$w$ & Weighing factor in parameter estimation \\
\hline $\mathbf{x}$ & Vector containing the control variables \\
\hline$x$ & Substrate conversion \\
\hline$X_{\text {crit }}$ & Critical conversion \\
\hline
\end{tabular}

\section{Greek letters}

$\begin{array}{ll}\alpha_{c, 0} & \text { Initial cellulose fraction of the solids } \\ \alpha_{c} & \text { Cellulose fraction of the solids during hydrolysis } \\ \rho_{\mathrm{s}} & \text { Bulk density of the substrate }\left(\mathrm{g}^{-1}\right) \\ \boldsymbol{\theta} & \text { Vector containing the model parameters }\end{array}$

\section{Abbreviations}

CC

Correlation coefficient 


\section{Introduction}

Production of glucose from the cellulose polymer is one of the key processing steps of producing fuels and chemicals from a lignocellulosic biomass in a biorefinery concept. Cellulose hydrolysis is performed generally by either enzymatic or chemical processes. Enzymatic hydrolysis of cellulose is characterized by the insoluble substrate and several types of enzymes that act on different parts of the cellulose chain, and the consequent degradation of the fiber and solubilization of cellodextrins and glucose. Two main groups of cellulases can be distinguished, endoglucanases and exoglucanases, which act within the cellulose chain and on the chain ends, respectively. In addition, $\beta$-glucosidase acts on soluble cellobiose and cellotriose to produce glucose. (Zhang and Lynd, 2004) Many of the factors influencing enzymatic hydrolysis cannot be quantified separately since they are interrelated and this adds challenges also to the description of the reaction kinetics. Despite this, several kinetic models for cellulose hydrolysis have been developed (Bansal et al., 2009).

Some models take into account the substrate morphology in a mechanistic sense (Zhang et al., 2014) or by fractal kinetics (Kostylev and Wilson, 2013; Väljamäe et al., 1999; Wang and Feng, 2010), degree of cellulose polymerization through population balance equations (Griggs et al., 2012; Hosseini and Shah, 2011; Lebaz et al., 2015) or some other phenomena that may affect the reaction rate. These include decrease in reaction rate with respect to conversion (Drissen et al., 2007; Kadam et al., 2004; Liao et al., 2008), reaction time (Ye and Berson, 2011) or due to competing reaction (Tsai et al., 2014). Also mass transfer limitations at high solids content has been discussed in literature although the results are not unambiguous. However, increased mixing power has been found to have a positive effect on glucose yield or, at least, the optimum mixing conditions has been established in many studies (Hodge et al., 2008; Kinnarinen et al., 2012; Palmqvist et al., 2016; Palmqvist and Liden, 2012; Samaniuk et al., 2011; Wojtusik et al., 2016). In addition, (Hodge et al., 2008) concluded that increasing initial solids concentrations above $20 \%$ reduced the conversion 
after 48 hours and the threshold value for solids concentration was even lower for shorter reaction times.

The decrease in glucose production rate with increasing conversion has been observed in batch hydrolysis experiments and in resuspension experiments, in which partially hydrolyzed substrate is washed and resuspended in fresh reaction media. Some authors have attributed the decrease in the reaction rate in resuspension experiments to depend, at least to some degree, on the decrease in the adsorption of enzymes per remaining substrate amount (Bansal et al., 2012; Ooshima et al., 1983). Similarly, (Nidetzky and Steiner, 1993) observed the decrease in adsorption per remaining substrate in batch hydrolysis and described the kinetic behavior in their model using different parameters for the easily hydrolysable and non-degradable fractions of the substrate. (Bansal et al., 2012) explained the decrease in adsorption and reaction rate mainly by the decrease in adsorption equilibrium constant of the Langmuir type adsorption model. Also contradictory results have been published where no decrease in the enzyme adsorption or initial reaction rate was observed with increasing conversion (Yang et al., 2006). However, the desorption procedure used by (Yang et al., 2006) was different from the others as they used proteases whereas (Bansal et al., 2012; Ooshima et al., 1983) used chemical washing methods. In addition to the decrease in the enzyme adsorption capacity of the partially hydrolyzed substrate, also a decrease in the specific activity of the adsorbed enzyme has been speculated to be at least one of the reasons for the observed decrease in reaction rate. This type of behavior, together with decreased adsorption capacity, was observed by (Bansal et al., 2012). Moreover, it has been attributed to be the leading cause for the decrease in observed hydrolysis rate in other studies (Converse et al., 1988; Drissen et al., 2007; Kurakake et al., 1995; Ooshima et al., 1991).

It is a well-known issue in the development of hydrolysis models that the identifiability of the parameters has remained poor or studies regarding the reliability and sensitivity of the parameters have been omitted although some studies include a rigorous assessment of the parameter uncertainty and model validity (Niu et al., 2016; Scott et al., 2015; Sin et al., 2010). Therefore, using the models for extrapolation should be done with caution. A large proportion of the modelling efforts has been done for batch processes, not for fed-batch processes investigated in this work. It 
is difficult to identify the effect of different rate decreasing factors based on the data from batch experiments with constant control variables. (Flores-Sánchez et al., 2013) used a model based nonlinear experimental design to improve the parameter identifiability. Their approach was to determine an optimal control profile for the temperature in a batch hydrolysis, which improved the quality of parameter estimates, especially for reaction rate constants and activation energies.

The goal of this study is to form a model that is applicable for the fed-batch operation of hydrolysis process aiming at high substrate concentration. It has been shown in previous studies that fed-batch operation can significantly reduce the overall energy and peak power consumption for agitation in a stirred tank reactor compared to batch-wise hydrolysis (Corrêa et al., 2016; Sotaniemi et al., 2016). Thus, this type of operation may be beneficial in an industrial process where both the power consumption and hydrolysis time are to be minimized. In addition, a fed-batch hydrolysis process with a high final solids content circumvents possible mass transfer limitations and practical issues with representative sampling in the initial stages of batch-wise hydrolysis.

In the proposed model, the substrate in fed-batch hydrolysis is discretized into subpopulations based on feeding time interval, and the rate-decreasing factors are dependent on the conversion of the subpopulation. Thus, performing fed-batch experiments should increase the information content of the experimental data that is used for model calibration and validation. The kinetic model is based on the Langmuir-type adsorption behavior of the enzyme, the reaction rate being proportional to the adsorbed enzyme concentration with competitive glucose inhibition. Different scenarios are tested to model the decrease in reaction rate with increasing conversion. In the proposed scenarios, the reaction rate is assumed to be dependent either on the decrease in enzyme adsorption, the decrease in the activity of adsorbed enzyme or both. The sensitivity of the model parameters is analyzed, the importance of the rate decreasing phenomena is assessed, and the model performance is also tested with literature data. 


\section{Materials and methods}

\subsection{Kinetic model for hydrolysis}

The following assumptions were made in the hydrolysis model. The substrate composition is structurally uniform and there is no distinction between the hydrolyzability of the amorphous or crystalline cellulose, which is in line with the current understanding of the cellulose hydrolysis with a complex cellulase system (Mansfield et al., 1999). In addition, the non-cellulosic part of the solids (filter paper) is assumed to be inert. There is no distinction made between endo/exo -enzyme behaviors. The $\beta$-glucosidase activity of the enzyme mixture used in this study is high, and negligible cellobiose concentrations were measured during the experiments. Therefore, it is assumed that the rate of cellobiose conversion to glucose is not a limiting factor and is not included explicitly in the model. Enzyme adsorption is assumed to follow the Langmuir-type adsorption behavior, and the reaction rate is first order with respect to the concentration of enzyme-substrate complexes. These are the common assumptions of all the models formed. Additional modifications that were applied to the model in order to capture the decrease in reaction rate are discussed in detail in the later sections.

The modelling approach used in this study includes two separate models with increasing model complexity. The simpler model includes only the enzyme adsorption and first order reaction of the enzyme-substrate complex. These phenomena are assumed to dominate in the very beginning of the hydrolysis. Thus, this model, referred to as the initial kinetic model, is used only with the data collected in the very beginning of the hydrolysis experiments (up to $30 \mathrm{~min}$ ). The initial kinetic model is used to estimate the Langmuir adsorption parameters and the reaction rate constant. Since the initial kinetic model omits some significant factors affecting the reaction rate during the extended hydrolysis process, a more complex model, referred to as the full model, is formed to enable describing these phenomena. The parameters estimated with the initial kinetic model are given to the full model, which includes other important phenomena such as competitive glucose inhibition and rate decreasing factors related to the substrate and enzyme behavior. Parameter estimation, with fixed adsorption and kinetic parameters, and model validation are then carried out for the full model using experimental data with hydrolysis times up to 48 hours and various reaction conditions. 
The models were built in Matlab (Mathworks, US) using Optimization Toolbox and Global Optimization Toolbox in the parameter estimation.

\subsubsection{Initial kinetics}

In the initial stages of the hydrolysis, the effect of the rate decreasing factors related to glucose inhibition or decrease in the enzyme adsorption and adsorbed enzyme activity can be assumed to be negligible. This is a feasible assumption as in the initial stages of hydrolysis the concentration of glucose is negligible and the substrate composition corresponds to the initial composition, i.e. the substrate conversion is negligible. Based on the previously stated assumptions, the initial kinetics of enzymatic hydrolysis are described by the following equations:

Langmuir adsorption isotherm

$$
E_{A}=\frac{E_{\mathrm{f}} S_{c} E_{\max 0}}{K_{\mathrm{L}}+E_{\mathrm{f}}},
$$

enzyme mass balance

$$
E_{\mathrm{f}}=E_{\mathrm{tot}}-E_{\mathrm{A}} \text {, }
$$

reaction rate equation

$$
r=k_{\max } E_{\mathrm{A}},
$$

and mass-balances for the substrate and glucose:

$$
\begin{aligned}
& \frac{d S_{c}}{d t}=-r, \\
& \frac{d G}{d t}=\frac{r}{0.9},
\end{aligned}
$$

where $E_{\mathrm{A}}$ is the adsorbed enzyme concentration $\left(\mathrm{g}_{\mathrm{p}} \mathrm{l}^{-1}\right), E_{\mathrm{f}}$ is the free enzyme concentration $\left(\mathrm{g}_{\mathrm{p}} \mathrm{I}^{-1}\right)$, $E_{\text {tot }}$ is the total enzyme concentration $\left(\mathrm{g}_{\mathrm{p}} \mathrm{I}^{-1}\right), S_{\mathrm{c}}$ is the cellulose concentration $\left(\mathrm{g}_{\mathrm{cel}} \mathrm{I}^{-1}\right), E_{\max 0}$ is the maximum amount of adsorbed enzyme per cellulose $\left(\mathrm{g}_{\mathrm{p}} \mathrm{g}_{\mathrm{cel}}{ }^{-1}\right), K_{\mathrm{L}}$ is the equilibrium constant $\left(\mathrm{g}_{\mathrm{p}} \mathrm{l}^{-1}\right)$, $r$ is the cellulose consumption rate $\left(g_{\text {cel }} l^{-1} h^{-1}\right), k_{\max }$ is the reaction rate constant $\left(g_{\text {cel }} g_{p}{ }^{-1} h^{-1}\right)$, and $G$ is the glucose concentration $\left(\mathrm{g}^{-1}\right)$. The concentration of the adsorbed enzyme can be calculated directly by inserting Eq. (2) to (1) and solving for $E_{\mathrm{A}}$ to yield: 


$$
E_{\mathrm{A}}=\frac{1}{2}\left[\left(E_{\mathrm{tot}}+E_{\max 0} S_{c}+K_{\mathrm{L}}\right)-\sqrt{\left(-E_{\mathrm{tot}}-E_{\max 0} S_{c}-K_{\mathrm{L}}\right)^{2}-4\left(E_{\mathrm{tot}} E_{\max 0} S_{c}\right)}\right],
$$

As stated earlier, only the small scale experimental data with approximately 30 min reaction time was used in the estimation of the parameters in the initial kinetics model $\left(E_{\max 0}, K_{\mathrm{L}}\right.$ and $\left.k_{\max }\right)$. The system of ordinary differential equations (ODEs, Eq. 4-5) was solved using the ode45 solver function. Parameter estimation was carried out by minimizing the sum of squared residuals between the model-estimated and measured glucose concentrations using a built-in function (Isqnonlin in Optimization Toolbox) for solving the following nonlinear least squares optimization problem.

$$
\min \sum_{j=1}^{n_{\text {exp }}}\left(f\left(\mathbf{x}_{j}, \boldsymbol{\theta}\right)-y_{j}\right)^{2},
$$

where $f\left(\mathbf{x}_{j}, \boldsymbol{\theta}\right)$ is the model predicted glucose concentration for experiment $j, \mathbf{x}_{j}$ is a vector of control variables $\left(E_{\mathrm{tot}}, S_{0}, t\right), \boldsymbol{\theta}$ is the parameter vector, $y_{j}$ is the measured glucose concentration for the corresponding experiment, and $n_{\exp }$ is the total number of experiments. The sensitivity function, sensitivity matrix, and parameter confidence intervals were calculated as described in the Supplementary material.

\subsubsection{Full model for fed-batch hydrolysis}

In the fed-batch experiments, the enzyme was added in the beginning of an experiment whereas the substrate was added on multiple occasions along the reaction time. In this study, as pointed out earlier, the description of this was enabled in the model by discretizing the substrate, i.e. forming a substrate population for each substrate addition. This means that the enzyme adsorption and mass balance Eqs. (1) and (2) are modified in the form:

$$
\begin{aligned}
& E_{\mathrm{A}, i}=\frac{E_{\mathrm{f}} S_{c, i} E_{\mathrm{max}, i}}{K_{\mathrm{L}}+E_{\mathrm{f}}}, \\
& E_{\mathrm{f}}=E_{\mathrm{tot}}-\sum E_{\mathrm{A}, i},
\end{aligned}
$$

where $i$ refers to the $i$ th substrate population. In addition to separate kinetic equations for substrate added at different times, the following phenomena were included in the model to account for the rate decreasing factors during hydrolysis for each substrate population: 
1) Decrease in the enzyme adsorption capacity with increasing conversion, Eqs. (10-11),

2) Competitive inhibition due to accumulation of glucose, Eq. (12), and

3) Decrease in the activity of adsorbed enzyme with increasing conversion, Eq. (13).

To account for the decrease in the adsorption capacity with increasing conversion, the value of $E_{\max }$ was assumed to decrease as a function of conversion for each substrate population. The decrease in enzyme adsorption capacity with increasing conversion has been observed in previous studies (Bansal et al., 2012; Converse et al., 1988; Ooshima et al., 1983). On the other hand, the decrease in the enzyme adsorption and reaction rate is negligible in the initial phase for hydrolysis at low conversions $(X<10 \%)$, and some minimum adsorption capacity is maintained even with extended hydrolysis times and conversions. Based on the previous literature results and our experimental results, the following criteria were demanded from the mathematical representation of this phenomenon. First, the amount of adsorbed enzyme per substrate does not approach zero with increasing conversion, but there is a minimum asymptotical value. Second, the decrease is not necessarily immediate at low conversion but there may be a range of conversions at which the enzyme adsorption capacity is equal to the adsorption capacity of fresh substrate. Finally, changes in $E_{\max }$ should be continuous and differentiable. Thus, the following sigmoidal function for $E_{\max }$ was formulated.

$$
E_{\max , i}=E_{\max 0}+\frac{\left(E_{\max , \min }-E_{\max 0}\right)}{1+\exp \left(-k_{\mathrm{Emax}}\left(X_{i}-X_{\text {crit }}\right)\right)},
$$

where $E_{\max }$ is the value estimated from the initial kinetics model and $E_{\max , \min }$ is the minimum value for the maximum adsorbed amount of enzyme, which was evaluated with

$$
E_{\text {max }, \min }=E_{\max 0}\left(\frac{E_{\text {tot }}}{\frac{\sum S_{c, i, A c c}}{V}}\right)^{n_{\text {Emax }}},
$$

where $S_{c, i \text { Acc }}$ is the mass of $i$ th addition of the substrate $(\mathrm{g}), V$ is the total volume of the slurry $(\mathrm{I}), X$ is the substrate conversion and $n_{\text {Emax }}, k_{\text {Emax }}$ and $X_{\text {crit }}$ are adjustable parameters. Eq. (10) is a sigmoid 
function with $E_{\max }$ is at the halfway of $E_{\max 0}$ and $E_{\max , \min }$ at $X=X_{\text {crit, }}$ and the steepness of the decrease in $E_{\max }$ depends on the parameter $k_{\max }$. As can be seen in Eqs. (10) and (11) the value for $E_{\max }$ depends on $E_{\text {tot, }}$ total accumulated substrate concentration and conversion of the substrate population. It is also notable that $E_{\max , \mathrm{i}}=E_{\max 0}$ if $X_{\mathrm{i}}=0$ and $E_{\max , \mathrm{i}}$ approaches $E_{\max , \min }$ with increasing $X_{\mathrm{i}}$.

Reaction rate for each substrate population is calculated with Eqs. (12) and (13). Equation (12) includes the inhibitive effect of glucose on the reaction rate.

$$
r_{i, 0}=\frac{k_{\max } E_{\mathrm{A}, i}}{1+\frac{G}{K_{\mathrm{l}, \mathrm{G}}}},
$$

where $K_{\mathrm{I}, \mathrm{G}}$ is the glucose inhibition constant. It was also assumed that, in addition to the proposed decrease in enzyme adsorption with increasing conversion, also the activity of the adsorbed enzyme decreases as described by Eq. (13).

$$
\frac{r_{i}}{r_{i, 0}}=\left(\frac{\sum E_{\mathrm{A}, i}}{\frac{\sum S_{c, i, \mathrm{Acc}}}{V} E_{\max 0}}\right)^{n_{0} \exp \left(q X_{i} \frac{\sum S_{c, i, \mathrm{Acc}}}{V}\right)},
$$

where $n_{0}$ and $q$ are adjustable parameters. Eq. (13) is similar to the one proposed by (Ooshima et al., 1991) but they had factor $\left(E_{\mathrm{A}} / E_{\text {tot }}\right)$ as the base of the relation. Based on the comparison between our experimental data and a model using the factor $\left(E_{\mathrm{A}} / E_{\text {tot }}\right)$ as the base in Eq. (13), led to less significant decreases in reaction rate at lower initial enzyme concentrations especially in fed-batch experiments with a high substrate concentration. Thus, the glucose concentrations were overpredicted in these conditions. Therefore, we included the substrate concentration dependency in the description of adsorbed enzyme activity decrease. The modification means that the decrease in the activity of the enzymes is related, rather than to the concentration of enzyme in the solution as proposed by Ooshima et al. (1991), to the initial maximum amount of adsorbed enzyme to the unconverted substrate. This is understandable as the equation describes unproductive binding of the enzymes and it occurs on the surface of the substrate, not in the solution. The exponent in Eq. 
(13) is similar to the one proposed by (Ooshima et al., 1991) but modified to include the presence of multiple substrate populations and fed-batch operation of hydrolysis.

Feed rate $\left(F, \mathrm{~g} \mathrm{~h}^{-1}\right)$ in the fed-batch experiments is determined from the experimental data, and dilution rate $D\left(h^{-1}\right)$ is calculated as

$$
D=\frac{F}{\rho_{\text {S,bulk }}} \frac{1}{V},
$$

where $\rho_{\mathrm{s}, \text { bulk }}$ is the bulk density of solid substrate $\left(\mathrm{gl}^{-1}\right)$ to account for increased slurry volume due to added substrate. The following equations describe the substrate mass balance for each substrate addition population (15), total accumulated amount of substrate for each addition (16), overall glucose concentration (17) and total volume (18).

$$
\begin{aligned}
& \frac{d S_{c, i}}{d t}=-r_{i}+D\left(S_{c, i, \mathrm{in}}-S_{c, i}\right), \\
& \frac{d S_{c, i, \mathrm{Acc}}}{d t}=F \\
& \frac{d G}{d t}=\frac{\sum r_{i}}{0.9}+D\left(G_{\mathrm{in}}-G\right), \\
& \frac{d V}{d t}=\frac{F}{\rho_{\mathrm{S}, \text { bulk }}}
\end{aligned}
$$

where the value of 0.9 accounts for the imbalance between the molar weights of cellulose and glucose in the hydrolysis reaction (i.e. $\frac{M_{\text {anyydroglu cose }}}{M_{\text {glumose }}}=0.9$ ). In order to circumvent the need of iteratively solving $E_{\mathrm{A}, \mathrm{i}}$ at each time instant, the adsorbed enzyme concentration balance was added to the model:

$$
\frac{d E_{\mathrm{A}, \mathrm{i}}}{d t}=k_{\mathrm{Ads}}\left(E_{f} S_{\mathrm{c}, i} E_{\mathrm{max}, i}-\left(K_{\mathrm{L}}+E_{\mathrm{f}}\right) E_{\mathrm{A}, j}\right),
$$

where $k_{\text {Ads }}$ is the adsorption rate constant. A similar approach to adsorption rate dynamics was used by (Shao et al., 2009) who used this approach to circumvent iterative calculations in a model for continuous simultaneous saccharification and fermentation. Their model also included several substrate populations and was later used in a CFD-model. We used a large value for the adsorption rate constant $\left(k_{\mathrm{Ads}}=10^{3} \mathrm{Ig}_{\mathrm{p}}{ }^{-1} \mathrm{~h}^{-1}\right)$ to ensure reaching fast the steady-state for $E_{\mathrm{A}, \mathrm{i}}$. 
By solving the model described above, we obtain the overall glucose concentration in the whole slurry volume. However, the measured glucose concentrations from the experiments are available only for the liquid phase. Therefore, the calculated values were converted to the liquid phase glucose concentrations with:

$$
\begin{aligned}
& G_{\text {liq }}=G /\left(1-\frac{S_{\mathrm{s}}}{\rho_{\mathrm{s}}}\right), \\
& S_{\mathrm{s}}=\frac{S_{\mathrm{c}}}{\alpha_{c}} \\
& \alpha_{c}=\frac{1-X}{\frac{1}{\alpha_{c, 0}}-X},
\end{aligned}
$$

where $S_{s}$ is the concentration of total solids $\left(\mathrm{g} \mathrm{I}^{-1}\right), \alpha_{c}$ is the fraction of the cellulose remaining in the solids and $\alpha_{c, 0}$ is the original cellulose fraction of the solids.

The ODE-system (equations 15 - 19) was solved by ode15s solver function. The parameters for the full model were estimated by minimizing the equation (23). The search for the global minimum of Eq. (23) was carried out in two stages. A genetic algorithm (ga in Global Optimization Toolbox) was used in the initial phase which was followed by a derivative based method (fmincon in Optimization Toolbox).

$$
\begin{aligned}
& \min J(\boldsymbol{\theta})=\min \sum_{j=1}^{n_{\mathrm{exp}}}\left[\sum_{k=1}^{n_{m, i}}\left(f\left(\mathbf{x}_{j, k}, \boldsymbol{\theta}\right)-y_{j, k}\right)^{2} w_{j}\right], \\
& w_{j}=\frac{\bar{n}_{m}}{n_{\mathrm{m}, j}}\left(\frac{\bar{y}_{n_{m}}}{y_{j, n_{\mathrm{m}, j}}}\right),
\end{aligned}
$$

where $w_{j}$ is the weighing factor for experiment $j$. Weighting factors were calculated based on the total number of measurements in the experiment $\left(n_{m, j}\right)$ and the final glucose concentration of the experiment $\left(y_{j, n m, j}\right)$. The multipliers $\bar{n}_{m}=6$ and $\bar{y}_{n_{m}}=50 \mathrm{~g} / \mathrm{l}$ were chosen to represent typical values for the number of measurements and final glucose concentration.

In addition to the above presented model, reduced form of the model was used to fit the data to see if some of the rate-decreasing phenomena (adsorbed enzyme activity, enzyme adsorption or 
glucose inhibition) could be omitted. F-ratio test was used to compare the full and reduced models with lower number of adjustable parameters in a similar manner as (Scott et al., 2015). For model 2 (full model) and 1 (restricted model) with $p_{2}>p_{1}$ number of parameters, the $F$-statistic can be calculated as

$$
F_{\text {stat }}=\frac{\left(\frac{J\left(\boldsymbol{\theta}_{1}\right)-J\left(\boldsymbol{\theta}_{2}\right)}{p_{2}-p_{1}}\right)}{\left(\frac{J\left(\boldsymbol{\theta}_{2}\right)}{n_{\text {meas }}-p_{2}}\right)},
$$

where $n_{\text {meas }}=104$ is the total number of measurement in all experiments used in the parameter estimation. Critical value for $F$-statistic can be calculated from the inverse of cumulative $F$ distribution with $p_{2}-p_{1}$ and $n_{\text {meas }}-p_{2}$ degrees of freedom. False detection probability of 0.05 was used in this work. In the F-test, null hypothesis is stated so that the more complex model (the full model) does not provide significantly better fit than the simplified model. The null hypothesis is rejected if the calculated $F$-statistic is larger than the critical value.

\subsection{Experimental methods}

All hydrolysis experiments were carried out in a $50 \mathrm{mM}$ sodium citrate - citric acid buffer. The measured pH of the buffer was 4.8. Qualitative filter paper, 600 (VWR International Europe BVBA, Belgium) was used as the substrate, and the cellulose content was measured to be $79 \%$ by the method described in (Sluiter et al., 2012). Flashzyme ${ }^{\mathrm{TM}}$ Plus $2 \mathrm{G}$ (Roal Oy, Finland) was used as the enzyme mixture, and the filter paper activity of the enzyme mixture is $111 \mathrm{FPU} / \mathrm{ml}$ and the cellobiase activity is $450 \mathrm{CB} / \mathrm{ml}$ (Sotaniemi et al., 2016). The protein concentration of the enzyme mixture was estimated to be $208 \mathrm{~g} / \mathrm{I}$ by A280 assay of Nanodrop spectrophotometer (Thermo Scientific, US).

\subsubsection{Hydrolysis experiments in small-scale}

The small-scale hydrolysis experiments were conducted in $2 \mathrm{ml}$ centrifuge tubes with a total suspension volume of $1.6 \mathrm{ml}$. Substrate was weighed to pre-weighed tubes, then the buffer solution was added to each tube and finally the tubes were placed to a heater-shaker (Thermomixer Comfort, Eppendorf, Germany) to reach the reaction temperature $\left(50^{\circ} \mathrm{C}\right)$. After at least 10 minutes of 
incubation, enzyme was added to each tube to start the reaction. No samples were drawn from the tubes due to the small volume but tubes with identical initial volumes and compositions were prepared to allow forming a series of measurements with different reaction times. After reaching the end of the reaction time, the corresponding tubes were placed to boiling water for 10 minutes to inactivate the enzymes, then cooled down with ice and centrifuged for 5 minutes at $16000 \mathrm{rcf}$. Supernatant was removed for glucose analysis with YSI2700 biochemistry analyzer (Yellow Springs Instruments, US), and samples were diluted with the reaction buffer if necessary.

In order to estimate the values for parameters that affect the initial kinetics, hydrolysis experiments with a $30 \mathrm{~min}( \pm 1 \mathrm{~min})$ reaction time were used to calculate the initial glucose release rate. These experiments were run in triplicates, and the initial enzyme and substrate concentrations used in these experiments are shown in Figure 1a. Batch hydrolysis experiments with a longer reaction time (24 h) were carried out with

- $\quad 30 \mathrm{~g} \mathrm{l}^{-1}$ solids content and 5, 10, 15 or $20 \mathrm{FPU} \mathrm{g}_{\mathrm{sol}}{ }^{-1}$ enzyme dosage, and

- $5,10,40$ and $50 \mathrm{~g} \mathrm{l}^{-1}$ solids content and $10 \mathrm{FPU} \mathrm{g}_{\mathrm{sol}}{ }^{-1}$ enzyme dosage.

The enzyme dose is in the basis of total solids. The sampling times in the batch experiments were $0.5,1,2,4,6$ and $24 \mathrm{~h}$. The experiment with $30 \mathrm{~g} / \mathrm{l}$ solids and $10 \mathrm{FPU} / \mathrm{g}_{\text {sol }}$ enzyme was run in four replicates, from which the standard deviation was estimated to be $10 \%$ of the average measured glucose. This value was used in the Monte Carlo simulations for the full model, described in the later sections.

In addition to the batch experiments, fed-batch experiments with one substrate addition were carried out in the small scale. The total amount of solids added during the fed-batch experiments corresponds to having initial solids concentration of $60 \mathrm{~g}^{-1}$ in a batch experiment. In the fed-batch experiments, half of the substrate was added initially, and the rest after 5 or 24 hours from the start

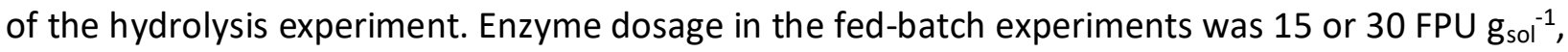
calculated on the basis of the total amount of added solids. 


\subsubsection{Fed-batch hydrolysis in reactor}

Fed-batch experiments were carried out in a 3 liter stirred tank reactor (Applikon Biotechnology B.V., Netherlands) equipped with a heating jacket to allow maintaining a constant temperature of $50{ }^{\circ} \mathrm{C}$. The reactor diameter was $13 \mathrm{~cm}$ and a down pumping pitched blade impeller with a diameter of $5.9 \mathrm{~cm}$ was used for mixing at impeller revolution rates of 300,400 or $500 \mathrm{rpm}$. More detailed information of the reactor system can be found in (Sotaniemi et al., 2015).

Prior to starting a fed-batch experiment, the reactor was filled with $800 \mathrm{ml}$ of the buffer solution and $30 \mathrm{~g}$ of the substrate. The reaction was started by adding enzyme solution corresponding to 5 , 10 or $15 \mathrm{FPU} \mathrm{g}_{\mathrm{sol}}{ }^{-1}$ calculated based on the total added solids. During the experiment, substrate was added so that the total amount of accumulated substrate would correspond to $200 \mathrm{~g} / \mathrm{l}$ when calculated on the basis of the final volume. The addition of the substrate was carried out using either predetermined schedule where additions were made every one hour or by maintaining the stirring power at a constant level. The experiments with constant stirring power during the feeding phase were carried out by two-level full factorial design with variable stirrer speed, agitation power during substrate feeding phase, and enzyme dosage. Three replicate experiments were carried out for the so-called center-points of the experimental design, and standard deviation for glucose was calculated from the center-point experiments. Sample handling was similar to the small scale experiments, but the samples were not boiled but instead maintained in ice after sampling and stored frozen. A more detailed description of the fed-batch experiments can be found from (Sotaniemi et al., 2016).

\section{Results and discussion}

\subsection{Model parameter estimation}

\subsubsection{Initial kinetics}

The data from the small scale hydrolysis experiments with a reaction time of 30 minutes were used to fit the parameters $\left(E_{\max }, K_{\mathrm{L}}\right.$ and $\left.k_{\max }\right)$ in the model describing the initial kinetics without rate decreasing factors (Eqs. (1) - (6)). The estimated parameters with $95 \%$ confidence intervals are presented in Table 1 . The adsorption parameters $E_{\max , 0}$ and $K_{\mathrm{L}}$ are in the same range as reported 
previously by (Kumar and Wyman, 2009) for different substrates $\left(E_{\max }=0.084-0.134 \mathrm{~g}_{\mathrm{p}} \mathrm{g}_{\mathrm{s}}{ }^{-1}\right.$ and $K_{\mathrm{L}}$ $\left.=0.02-1.14 \mathrm{~g}_{\mathrm{p}} \mathrm{l}^{-1}\right)$. A contour plot of the model-estimated initial glucose release rates is presented in Figure 1a.

The highest glucose release rate during the first 30 minutes is estimated when both the enzyme dosage and the initial substrate concentration are high, as would be expected. Similarly, low release rate was estimated when either or both of the variables are low. Thus, the model used for initial kinetics description appears to give qualitatively feasible trends. The quantitative analysis of the model can be viewed from a parity plot of calculated vs. measured glucose release rates in Figure 1b. The initial glucose release rate calculated by the model is close to the measured values throughout the investigated domain, and the $R^{2}$-value is 0.97 .

The value of the objective function and the estimated correlation coefficients for the three parameter pairs is presented in Figure 2a-c. An additional assessment for the parameter estimation was carried out by Monte Carlo simulations (MC) in which the parameters were estimated for 1000 data sets generated from the actual experimental data. A random number from a normal distribution with mean and variance estimated from the experimental data was used in the MC parameter estimation for each experimental point presented in Figure 1a. The estimated parameters and correlation coefficients are presented in Figure 2a-c and histogram plots of the estimated parameters in Figure 2d-f.

As can be seen in Figure 2a-c, the parameter pairs $\left(k_{\max }-E_{\max }\right.$ and $\left.k_{\max }-K_{\mathrm{L}}\right)$ are to a certain degree correlated, but the values of the correlation coefficients deviate clearly from the value of 1 . Parameters estimated from the Monte Carlo simulations are scattered quite well in line with the contour lines, and the mean parameter values calculated from the simulations are within $2.5 \%$ from the original parameters. The distribution of the parameters from Monte Carlo simulations follow normal distribution (Figure 2d-f), and the 95\% confidence intervals were estimated to lie within \pm 1.96 standard deviations from the mean value (shown in Table 1). The confidence interval from MC-simulation for $E_{\max , 0}$ is wider than estimated from the parameter estimation, while it is tighter for $k_{\max }$ and, especially, $K_{\mathrm{L}}$. Thus, we can conclude that although some of the parameter pairs are to 
some degree correlated, they have significance on the model predictions. In addition, the values of the initial kinetics parameters have been identified well.

Finally, the validity of the assumption of negligible rate decreasing factors during the first 30 minutes was evaluated by using the full model, described in the next section, to predict the glucose concentrations in the experimental conditions of the initial kinetics studies. The deviation between the glucose concentrations estimated by the initial kinetic model and the full model was small as can be seen in Figure 1b. The maximum difference in the glucose concentrations calculated by the two models was $3 \%$, the average difference being less than $1 \%$. Therefore, the approach to estimate parameters separately for the initial kinetics and full model can be considered adequate.

\subsubsection{Full model}

For the fed-batch hydrolysis, different scenarios of the proposed model were tested in order to assess the significance of the rate-decreasing factors (glucose inhibition, decrease in the enzyme adsorption per substrate, and decrease in the adsorbed enzyme activity). In addition, the significance of the substrate discretization to multiple substrate populations was assessed by comparing the results of the model with and without the discretization. When only one substrate population was applied to describe an experiment with multiple substrate additions (not discretized case), the fed-batch model was modified to enable this. In this modification, the substrate conversion $\left(X_{i}\right)$ in equations (11) and (13) was calculated using the overall conversion of the substrate. In total eight small scale batch experiments, six small scale fed-batch experiments, and three reactor scale fed-batch experiments were used in the parameter estimation. The substrate feeding in all reactor scale fed-batch experiments used in the estimation was the same. The substrate feeding was performed by maintaining the stirring power at a constant level during the feeding phase.

The estimated parameter values are presented in Table 2. Simplified models A, B and C are the models omitting the decrease in adsorbed enzyme activity, decrease in the enzyme adsorption capacity, and glucose inhibition, respectively. As the maximum glucose concentration in the experiments was approximately $100 \mathrm{~g} / \mathrm{l}$, the glucose inhibition in equation (12) becomes negligible 
when $K_{\mathrm{I}, \mathrm{G}}$ is fixed to a large value and hence $K_{\mathrm{I}, \mathrm{G}}=10^{6} \mathrm{~g} / \mathrm{I}$ was used for the simplified model $\mathrm{C}$. For the simplified models $A$ and $B$, the corresponding parameters for omitted phenomena were set to zero.

An additional assessment of the parameter quality was carried out for the full model with similar Monte Carlo calculations as with the initial kinetics model. Similar estimation scheme (genetic algorithm followed by a derivative-based method) was used as in the actual parameter estimation, and 50 sets of parameter values near the previously estimated values (shown in Table 2), were added to the initial population of the genetic algorithm. In addition, the value of the objective function (Eq. 23) was estimated for each parameter pair while maintaining the other parameters at their optimal values. The estimated parameters and contour plot of the objective function are presented in Figure $2 \mathrm{~g}$ for each parameter pair, and a histogram of the estimated values is given for each parameter.

Most of the estimated parameters are very near to the likeliest parameter value, and the majority of the scattering of the parameters follows the normal distribution. However, for $K_{1, G}$, the distribution of the estimated values differs significantly from the normal distribution. The distribution of $K_{\mathrm{I}, \mathrm{G}}$ is essentially divided into two smaller distributions, one for the clearly smaller values and the other one for the higher values of the range. The low sensitivity of the parameter $K_{\mathrm{I}, \mathrm{G}}$ can also be observed from the objective function contour plots as $K_{\mathrm{I}, \mathrm{G}}$ has little effect on the function value. This implies that the glucose inhibition has low effect on the behavior of the fedbatch enzymatic hydrolysis in the range of the performed experiments. In addition to $K_{\mathrm{I}, \mathrm{G}}$, the sensitivity $k_{\text {Emax }}$ is low and, furthermore, the objective function value is not a smooth function of $k_{\text {Emax. }}$. Some significant parameter correlations are also detected from the MC simulations, especially for $n_{0}-q$ and $q-n_{E \max }$ pairs. Judging from the shape of the contour lines, there are potential correlations between most of the parameters as the contours are not circular but elongated.

\subsection{Hydrolysis kinetics using the full model}

After estimating the parameters linked to the rate-decreasing factors, the fit of the full model to different types of batch and fed-batch experiments both in small and reactor scale are investigated. 
In addition, the predictive capabilities of the full model are evaluated. The batch experiment results in small scale are presented in Figure 3a-b. The full model fits well to the experimental data in the small scale batch experiments although the final conversion with high enzyme dosages (15 and 20 FPU/g) are somewhat underestimated. The small-scale fed-batch experiment results are illustrated in Figure 3c-d.

It can be stated that the full model also captures well the increase in the reaction rate after substrate addition in fed-batch experiments. In addition to the fed-batch experiments with only two substrate populations, the model works well also in the description of a reactor scale fed-batch process behavior with continuous substrate feeding and multiple populations. This is shown in Figure $3 e$ with three different enzyme dosages (5, 10 and $15 \mathrm{FPU} / \mathrm{g}$ ) and a final solids concentration of 200 $\mathrm{g} / \mathrm{l}$. The stirring power was maintained constant in the fed-batch experiments shown in Figure 3e. The duration of the feeding phase in the experiments was in the range of three to five hours, the shortest feeding time being for the experiments with the highest enzyme dosage. As the hydrolysis proceeds, the fiber structure is disintegrated and also the solids concentration decreases, thus lowering both the viscosity of the slurry and the power required for mixing at a constant agitation rate. This allows higher feeding rate with higher enzyme dosage.

The previous examples are with the data used for parameter estimation. In order to assess the model response to rate decreasing factors in hydrolysis with a high solids loading, an additional experiment was conducted by performing a substrate addition also at 26 hours, significantly after the initial feeding phase. This experiment is shown in Figure $3 f$. The model response to the substrate addition at 26 hours is good although it seems to overpredict the increase in the reaction rate after the first few hours whereas the final increase in the glucose concentration at 48 hours is underpredicted. A similar trend can be observed in the small scale fed-batch experiments in Figure $3 c-d$ as the model-predicted glucose concentration is higher compared to the measured value at 26.5 hours for the substrate addition at 24 hours.

One explanation for this sort of behavior could be in the kinetics of cellulase adsorption. The model assumes immediate equilibrium in the enzyme adsorption, described by the Langmuir adsorption 
isotherm. However, it may be that the observed delay in the increase of the reaction rate after substrate addition is due to the adsorption kinetics of the enzyme. (Eriksson et al., 2002) used pure enzyme preparations of exoglucanase (Cel7A) and endoglucanase (Cel7B) to study the effect of enzyme and substrate additions after 24 hours of hydrolysis of steam pretreated spruce with exoglucanase. The addition of substrate at 24 hours increased the glucose production rate although the initially added exoglucanase was almost completely adsorbed to the remaining substrate. Thus, a fraction of the adsorbed enzymes, exhibiting rather low catalytic activity after 24 hours, were desorbed from the initial substrate and adsorbed to the fresh substrate. This sort of behavior may be a reason for the observed delay in the glucose production after the substrate addition in our experiments. It should be noted that the enzyme concentrations and the enzyme-substrate ratios used by (Eriksson et al., 2002) were low, and the measured glucose concentrations were less than 1 $\mathrm{g} / \mathrm{I}$ meaning conversion below $10 \%$. Thus, the reaction conditions were different compared to our experiments with relatively high concentration of both substrate and enzyme.

Fed-batch experiments and the corresponding model description give insight on the rate decreasing factors observed in enzymatic hydrolysis of cellulose. It is evident that, despite the gradual decrease in the reaction rate with increasing conversion, enzymatic activity remains high during the fed-batch experiments up to 48 hours. Thus, the reaction rate of the fresh substrate is comparable to the reaction rate of the initial substrate. As a whole, the model is capable of predicting qualitatively the behavior, but there are still challenges in the quantitative predicting capabilities. Nevertheless, the differences between the model predicted and the experiment observed glucose concentration values are not large considering the wide range of operational conditions used in the experiments. An overall view of the model fit can be seen from the parity plot in Figure 4, which shows the measured and model predicted glucose concentrations for all experimental points including those that were not used in the parameter estimation. Glucose concentrations predicted by the model are mainly within $15 \%$ of the measured values. The few exceptions are from the initial phase of some fed-batch experiments.

In order to assess the model performance outside our own experimental system, the model was used to predict hydrolysis data from the literature with similar raw materials and enzyme. The data 
used in this comparison was from (Boussaid and Saddler, 1999; Kristensen et al., 2009). Both authors used a mixture of Cellulast (a cellulase mixture) and Novozym 188 ( $\beta$-glucosidase preparation) enzyme preparations on slightly different proportions. Therefore, the enzyme amount used in the references was scaled to be used in our model by using the reported filter paper units. The experimental conditions were filter paper with $5 \%$ or $20 \%$ solids loading and $10 \mathrm{FPU} / \mathrm{g}$ enzyme dosage (Kristensen et al., 2009) or softwood kraft pulp with $2 \%$ solids loading and 60 or $300 \mathrm{FPU} / \mathrm{g}$ enzyme dosage (Boussaid and Saddler, 1999). The results are shown in Figure 5 . The model is capable of predicting the time vs. conversion data in all cases. The largest deviation between the model and experimental data are with $2 \%$ solids loading and $60 \mathrm{FPU} / \mathrm{g}$ enzyme dosage where the conversions are underpredicted by the model especially at reaction times from 10 to 20 hours. However, the final conversion at 48 hours predicted by the model is already close to the experimental value. Otherwise, the model predictions are quite good even with hydrolysis times extended to 96 hours and very large enzyme dosage of 300 FPU per gram dry matter. Reaction times this long or such high enzyme dosages were not included in our experiments.

\subsection{Simplified models}

Although the full model fitted the experimental data well and showed good predicting capabilities when the simulated values were compared with literature data, it may suffer from over parametrization and exhibit rate-decreasing factors that have less significance than the others. The significance of the different rate-decreasing factors can be investigated by using the simplified models shown in Table 2 with different batch and fed-batch experiment data. Decrease in the adsorbed enzyme activity, decrease in the enzyme adsorption capacity or glucose inhibition were omitted in simplified models A, B and C, respectively. Batch experiments with two enzyme dosages (5 and $20 \mathrm{FPU} / \mathrm{g}$ ) and initial solids concentrations (10 and $40 \mathrm{~g} / \mathrm{l}$ ) are presented in Figure 6a-b, and fed-batch experiments with continuous feeding and 5 or 15 FPU/g enzyme dosage in Figure $6 \mathrm{c}$.

The simplified models B and C fit the batch data quite well whereas the simplified model A deviates from the experimental values especially at the later stage of hydrolysis when glucose concentration is high (20 FPU/g or $40 \mathrm{~g} / \mathrm{l}$ ). Furthermore, the shape of the curve seems improbable as the initial rate is quite high without significant decrease until a rapid decrease over a short period of time. 
Thus, the rate of decline predicted by the model is higher than in any of the performed experiments of this study. After this, the rate remains almost constant. This is due to the high value of $k_{\operatorname{Emax}}(44)$, which causes the value of $E_{\max }$ in Eq. (10) to decrease very steeply with conversion around the critical value of 0.21 . The simplified model $B$, with no decrease in the enzyme adsorption capacity, performs well in the batch experiments but underpredicts glucose concentrations in the beginning of $5 \mathrm{FPU} / \mathrm{g}$ fed-batch experiment. Also the final glucose in the $15 \mathrm{FPU} / \mathrm{g}$ fed-batch experiment are overpredicted by over $20 \%$.

Quantitative comparison of the simplified models and the full model was calculated from the $F$ statistic presented in equation 25 to test if there is significant improvement when using the full model with larger number of parameters compared to simplified models. The values of $F$-statistic and critical $F$-statistic are presented in Table 2 . The calculated $F$-statistics are larger than the critical value, and the null hypothesis can be rejected for all simplified models. That is, the full model does provide better fit compared to the simplified models.

Based on the combined data of the batch and fed-batch experiments, the simplified model $\mathrm{C}$ with no glucose inhibition performs best of the simplified models. It also has the lowest $F$-value although it still larger than the critical value. The largest deviation for the simplified model $C$ is in the batch experiment with a high enzyme dosage, in which the final predicted glucose concentration is lower than the measured value. The full model predicts the hydrolysis kinetics with a higher accuracy than the simplified model $\mathrm{C}$. Thus, all the rate-decreasing factors appear to have significance in the investigated conditions, but the glucose inhibition seems to have the least significance on the hydrolysis kinetics. This is in line with the parametric studies, in which $K_{\mathrm{l}, \mathrm{G}}$ was found to have low sensitivity.

\subsection{Model with a single substrate population}

In addition to the rate-decreasing factors, the full model includes the discretization of the substrate based on the addition time. The feasibility of this approach is investigated by comparing the full model with and without the discretization. In the full model with separate substrate populations, conversion of the each substrate population is calculated separately and, therefore, the rate- 
decreasing factors related to substrate conversion are calculated individually for each substrate population. Instead, the model with no substrate discretization and a single substrate population uses the overall conversion in the calculation of the rate-decreasing factors. A comparison of the full model with and without discretization is shown in Figure $6 \mathrm{~d}-\mathrm{f}$ for small scale and reactor scale fed-batch experiments.

The model with no substrate discretization predicts less significant increase in the glucose production rate than the model with substrate discretization when new substrate is added. The difference between the two models becomes most evident in the fed-batch experiment with an addition at 26 hours (Figure 6e-f). The last addition has practically no effect in the glucose concentration profile predicted by the full model without discretization whereas a significant increase in the glucose production rate is predicted by the full model with discretization. The difference between the model predictions can be viewed more in detail from Figure $6 f$ in terms of substrate conversion.

As can be seen in Figure $6 \mathrm{f}$, the overall conversion calculated on the basis of the total amount of substrate added decreases from $39 \%$ to $34 \%$ due to the addition of substrate at 26 hours with both models. This has only minor effects in the magnitude of the rate-decreasing factors in Eqs. (10) and (13). Thus, the predicted increase in glucose production rate is small. However, the addition of fresh substrate at 26 hours has a large effect on the glucose production rate in the full model in which the rate equation is evaluated separately for each substrate population. Although the effect of additions is significantly underestimated by the full model without discretization, the predicted glucose concentrations in the beginning of fed-batch hydrolysis are still very similar to the ones of the full model.

Based on Figure $6 \mathrm{~d}-\mathrm{f}$, the discretization of the substrate into multiple substrate populations improves the prediction capabilities of the model qualitatively and quantitatively especially when the added substrate amount is low in comparison to the substrate already present in the reactor but large enough to cause a significant increase in the glucose production rate. Furthermore, these results further emphasize that there is still significant amount of active enzyme after 24 hours even 
though the reaction rate of the initially added substrate has already decreased significantly and the conversion of the initially fed substrate is still relatively low. Thus, both the substrate discretization and the proposed rate-decreasing factors have an impact on the kinetics, the relative importance being dependent on the process conditions and feeding schedule.

It is evident that the sensitivity of the model with respect to the parameters changes with time in a dynamic system. Furthermore, the rate-decreasing phenomena are dependent on the substrate conversion, and the sensitivity is also strongly affected by the feeding schedule. This study focused mainly on formulating a model to be used for a fed-batch hydrolysis with a short feeding phase in the initial phase. However, a more detailed dynamic sensitivity analysis of the model could be used to plan experimental conditions to increase the information content of the experiments and help to elucidate the effect of the proposed rate decreasing phenomena.

\section{Conclusions}

The model describes first order reaction of the adsorbed enzyme, and the substrate is discretized based on the addition time for a fed-batch process. Adsorption parameters and the activity of the adsorbed enzyme are affected by the substrate conversion. The model is applicable for the description of a broad range of operating conditions, and it also predicted well hydrolysis data from the literature. Model parameter estimation and sensitivity analysis were carried out successfully. The use of non-constant control variables in experiments is a potential approach to increase the information content of the experiments and reliability of the model.

\section{Acknowledgements}

Petri Tervasmäki acknowledges Fortum foundation for a personal research grant (201500179). Jani Kangas acknowledges the funding of Academy of Finland (project no. 286633).

\section{References}

1. Bansal, P., Hall, M., Realff, M.J., Lee, J.H., Bommarius, A.S., 2009. Modeling cellulase kinetics on lignocellulosic substrates. Biotechnol. Adv. 27, 833-848. 
2. Bansal, P., Vowell, B.J., Hall, M., Realff, M.J., Lee, J.H., Bommarius, A.S., 2012. Elucidation of cellulose accessibility, hydrolysability and reactivity as the major limitations in the enzymatic hydrolysis of cellulose. Bioresour. Technol. 107, 243-250.

3. Boussaid, A., Saddler, J.N., 1999. Adsorption and activity profiles of cellulases during the hydrolysis of two Douglas fir pulps. Enzyme Microb. Technol. 24, 138-143.

4. Converse, A.O., Matsuno, R., Tanaka, M., Taniguchi, M., 1988. MODEL OF ENZYME ADSORPTION AND HYDROLYSIS OF MICROCRYSTALLINE CELLULOSE WITH SLOW DEACTIVATION OF THE ADSORBED ENZYME. Biotechnol. Bioeng. 32, 38-45.

5. Corrêa, L.J., Badino, A.C., Cruz, A.J.G., 2016. Power consumption evaluation of different fed-batch strategies for enzymatic hydrolysis of sugarcane bagasse. Bioprocess Biosyst. Eng. 39, 825833.

6. Drissen, R.E.T., Maas, R.H.W., Maarel, M.J.E.C. van der, Kabel, M.A., Schols, H.A., Tramper, J., Beeftink, H.H., 2007. A generic model for glucose production from various cellulose sources by a commercial cellulase complex. Biocatal. Biotransformation 25, 419-429.

7. Eriksson, T., Karlsson, J., Tjerneld, F., 2002. A model explaining declining rate in hydrolysis of lignocellulose substrates with cellobiohydrolase I (Cel7A) and endoglucanase I (Cel7B) of Trichoderma reesei. Appl. Biochem. Biotechnol. 101, 41-60.

8. Flores-Sánchez, A., Flores-Tlacuahuac, A., Pedraza-Segura, L.L., 2013. Model-based experimental design to estimate kinetic parameters of the enzymatic hydrolysis of lignocellulose. Ind. Eng. Chem. Res. 52, 4834-4850.

9. Griggs, A.J., Stickel, J.J., Lischeske, J.J., 2012. A mechanistic model for enzymatic saccharification of cellulose using continuous distribution kinetics II: Cooperative enzyme action, solution kinetics, and product inhibition. Biotechnol. Bioeng. 109, 676-685.

10. Hodge, D.B., Karim, M.N., Schell, D.J., McMillan, J.D., 2008. Soluble and insoluble solids contributions to high-solids enzymatic hydrolysis of lignocellulose. Bioresour. Technol. 99, 8940-8948.

11. Hosseini, S.A., Shah, N., 2011. Enzymatic hydrolysis of cellulose part II: Population balance modelling of hydrolysis by exoglucanase and universal kinetic model. Biomass Bioenergy 35, 3830-3840.

12. Kadam, K.L., Rydholm, E.C., McMillan, J.D., 2004. Development and validation of a kinetic model for enzymatic saccharification of lignocellulosic biomass. Biotechnol. Prog. 20, 698-705.

13. Kinnarinen, T., Shakhanova, M., Hietanen, E., Salmimies, R., Häkkinen, A., Louhi-Kultanen, M., 2012. Effect of mixing on enzymatic hydrolysis of cardboard waste: Saccharification yield and subsequent separation of the solid residue using a pressure filter. Bioresour. Technol. 110, 405-411.

14. Kostylev, M., Wilson, D., 2013. Two-parameter kinetic model based on a time-dependent activity coefficient accurately describes enzymatic cellulose digestion. Biochemistry (Mosc.) 52, 5656-5664.

15. Kristensen, J.B., Felby, C., Jørgensen, H., 2009. Yield-determining factors in high-solids enzymatic hydrolysis of lignocellulose. Biotechnol. Biofuels 2, 11.

16. Kumar, R., Wyman, C.E., 2009. Cellulase adsorption and relationship to features of corn stover solids produced by leading pretreatments. Biotechnol. Bioeng. 103, 252-267. 
17. Kurakake, M., Shirasawa, T., Ooshima, H., Converse, A.O., Kato, J., 1995. An extension of the Harano-Ooshima rate expression for enzymatic hydrolysis of cellulose to account for changes in the amount of adsorbed cellulase. Appl. Biochem. Biotechnol. 50, 231-241.

18. Lebaz, N., Cockx, A., Spérandio, M., Morchain, J., 2015. Population balance approach for the modelling of enzymatic hydrolysis of cellulose. Can. J. Chem. Eng. 93, 276-284.

19. Liao, W., Liu, Y., Wen, Z., Frear, C., Chen, S., 2008. Kinetic modeling of enzymatic hydrolysis of cellulose in differently pretreated fibers from dairy manure. Biotechnol. Bioeng. 101, 441451.

20. Mansfield, S.D., Mooney, C., Saddler, J.N., 1999. Substrate and enzyme characteristics that limit cellulose hydrolysis. Biotechnol. Prog. 15, 804-816.

21. Nidetzky, B., Steiner, W., 1993. A new approach for modeling cellulase-cellulose adsorption and the kinetics of the enzymatic hydrolysis of microcrystalline cellulose. Biotechnol. Bioeng. 42, 469-479.

22. Niu, H., Shah, N., Kontoravdi, C., 2016. Modelling of amorphous cellulose depolymerisation by cellulases, parametric studies and optimisation. Biochem. Eng. J. 105, Part B, 455-472.

23. Ooshima, H., Kurakake, M., Kato, J., Harano, Y., 1991. Enzymatic activity of cellulase adsorbed on cellulose and its change during hydrolysis. Appl. Biochem. Biotechnol. 31, 253-266.

24. Ooshima, H., Sakata, M., Harano, Y., 1983. Adsorption of cellulase from Trichoderma viride on cellulose. Biotechnol. Bioeng. 25, 3103-3114.

25. Palmqvist, B., Kadić, A., Hägglund, K., Petersson, A., Lidén, G., 2016. Scale-up of high-solid enzymatic hydrolysis of steam-pretreated softwood: the effects of reactor flow conditions. Biomass Convers. Biorefinery 6, 173-180.

26. Palmqvist, B., Liden, G., 2012. Torque measurements reveal large process differences between materials during high solid enzymatic hydrolysis of pretreated lignocellulose. Biotechnol. Biofuels 5, 57.

27. Samaniuk, J.R., Scott, C.T., Root, T.W., Klingenberg, D.J., 2011. The effect of high intensity mixing on the enzymatic hydrolysis of concentrated cellulose fiber suspensions. Bioresour. Technol. 102, 4489-4494.

28. Scott, F., Li, M., Williams, D.L., Conejeros, R., Hodge, D.B., Aroca, G., 2015. Corn stover semimechanistic enzymatic hydrolysis model with tight parameter confidence intervals for model-based process design and optimization. Bioresour. Technol. 177, 255-265.

29. Shao, X., Lynd, L., Wyman, C., Bakker, A., 2009. Kinetic modeling of cellulosic biomass to ethanol via simultaneous saccharification and fermentation: Part I. accommodation of intermittent feeding and analysis of staged reactors. Biotechnol. Bioeng. 102, 59-65.

30. Sin, G., Meyer, A.S., Gernaey, K.V., 2010. Assessing reliability of cellulose hydrolysis models to support biofuel process design-Identifiability and uncertainty analysis. Comput. Chem. Eng. 34, 1385-1392.

31. Sluiter, A., Hames, B., Ruiz, R., Scarlata, C., Sluiter, J., Templeton, D., 2012. Determination of Structural Carbohydrates and Lignin in Biomass.

32. Sotaniemi, V.-H., Taskila, S., Ojamo, H., Tanskanen, J., 2016. Controlled feeding of lignocellulosic substrate enhances the performance of fed-batch enzymatic hydrolysis in a stirred tank reactor. Biomass Bioenergy 91, 271-277. 
33. Sotaniemi, V.-H., Tikkanen, T., Pasanen, A., Taskila, S., Ojamo, H., 2015. Effect of enzyme and substrate dosing strategies on mixing and hydrolysis of old corrugated cardboard. Biomass Convers. Biorefinery 5, 141-148.

34. Tsai, C.-T., Morales-Rodriguez, R., Sin, G., Meyer, A.S., 2014. A dynamic model for cellulosic biomass hydrolysis: A comprehensive analysis and validation of hydrolysis and product inhibition mechanisms. Appl. Biochem. Biotechnol. 172, 2815-2837.

35. Väljamäe, P., Sild, V., Nutt, A., Pettersson, G., Johansson, G., 1999. Acid hydrolysis of bacterial cellulose reveals different modes of synergistic action between cellobiohydrolase $I$ and endoglucanase I. Eur. J. Biochem. 266, 327-334.

36. Wang, Z., Feng, H., 2010. Fractal kinetic analysis of the enzymatic saccharification of cellulose under different conditions. Bioresour. Technol. 101, 7995-8000.

37. Wojtusik, M., Zurita, M., Villar, J.C., Ladero, M., Garcia-Ochoa, F., 2016. Influence of fluid dynamic conditions on enzymatic hydrolysis of lignocellulosic biomass: Effect of mass transfer rate. Bioresour. Technol. 216, 28-35.

38. Yang, B., Willies, D.M., Wyman, C.E., 2006. Changes in the enzymatic hydrolysis rate of avicel cellulose with conversion. Biotechnol. Bioeng. 94, 1122-1128.

39. Ye, Z., Berson, R.E., 2011. Kinetic modeling of cellulose hydrolysis with first order inactivation of adsorbed cellulase. Bioresour. Technol. 102, 11194-11199.

40. Zhang, Y., Xu, B., Zhou, W., 2014. On a novel mechanistic model for simultaneous enzymatic hydrolysis of cellulose and hemicellulose considering morphology. Biotechnol. Bioeng. 111, 1767-1781.

41. Zhang, Y.-H.P., Lynd, L.R., 2004. Toward an aggregated understanding of enzymatic hydrolysis of cellulose: Noncomplexed cellulase systems. Biotechnol. Bioeng. 88, 797-824. 


\section{Tables}

Table 1. Parameters for the initial kinetics with $95 \%$ confidence intervals estimated as described in the Supplementary data or from the Monte Carlo simulations (MC)

\begin{tabular}{llll}
\hline Parameter & Value & $95 \% \mathrm{Cl}$ & $95 \% \mathrm{Cl}(\mathrm{MC})$ \\
\hline$E_{\max , 0}\left(\mathrm{~g}_{\mathrm{p}} \mathrm{g}_{\mathrm{s}}^{-1}\right)$ & 0.0827 & $(0.08000 .0855)$ & $(0.06820 .0979)$ \\
$K_{\mathrm{L}}\left(\mathrm{g}_{\mathrm{p}} \mathrm{l}^{-1}\right)$ & 0.9747 & $(0.10181 .8477)$ & $(0.66971 .3223)$ \\
$k_{\max }\left(\mathrm{g}_{\mathrm{s}} \mathrm{g}_{\mathrm{p}}^{-1} \mathrm{~h}^{-1}\right)$ & 5.5482 & $(3.95307 .1433)$ & $(4.81276 .3697)$ \\
\hline
\end{tabular}

Table 2. Estimated parameter values for the full and simplified models, and the statistics for model comparisons. Critical $F$-statistic was calculated with false detection probability of 0.05 , and $6-(4,3$ or 5$)$ and $104-6$ degrees of freedom.

\begin{tabular}{|c|c|c|c|c|c|c|}
\hline \multirow[b]{2}{*}{ Parameter } & \multirow[b]{2}{*}{$\begin{array}{l}\text { Lower } \\
\text { bound }\end{array}$} & \multirow[b]{2}{*}{$\begin{array}{l}\text { Upper } \\
\text { bound }\end{array}$} & \multirow[b]{2}{*}{$\begin{array}{l}\text { Full model } \\
\text { estimation }\end{array}$} & \multicolumn{3}{|c|}{ Simplified model estimations } \\
\hline & & & & $A$ & $B$ & $\mathrm{C}$ \\
\hline$K_{\mathrm{I}, \mathrm{G}}\left(\mathrm{g}^{-1}\right)$ & 0 & 1000 & 139.56 & 25.84 & 62.53 & $10^{6}$ (fixed) \\
\hline$n_{0}(-)$ & 0 & 2 & 0.4864 & 0 (fixed) & 1.4972 & 0.5798 \\
\hline$q\left(\left|g_{c e l}\right|^{-1}\right)$ & 0 & 0.1 & 0.0115 & 0 (fixed) & 0.0071 & 0.0103 \\
\hline$n_{\operatorname{Emax}}(-)$ & 0 & 2 & 0.3563 & 0.7050 & 0 (fixed) & 0.4096 \\
\hline$k_{\operatorname{Emax}}(-)$ & 0 & 50 & 33.6963 & 44.3033 & 0 (fixed) & 27.7064 \\
\hline$X_{\text {crit }}(-)$ & 0 & 1 & 0.1964 & 0.2165 & 0 (fixed) & 0.1630 \\
\hline \multirow{3}{*}{\multicolumn{2}{|c|}{ Model comparisons }} & $J(\theta)$ & 215 & 756 & 1117 & 262 \\
\hline & & F-statistic & & 61.8 & 134 & 4.33 \\
\hline & & Critical $F$ & & 2.46 & 2.70 & 2.31 \\
\hline
\end{tabular}



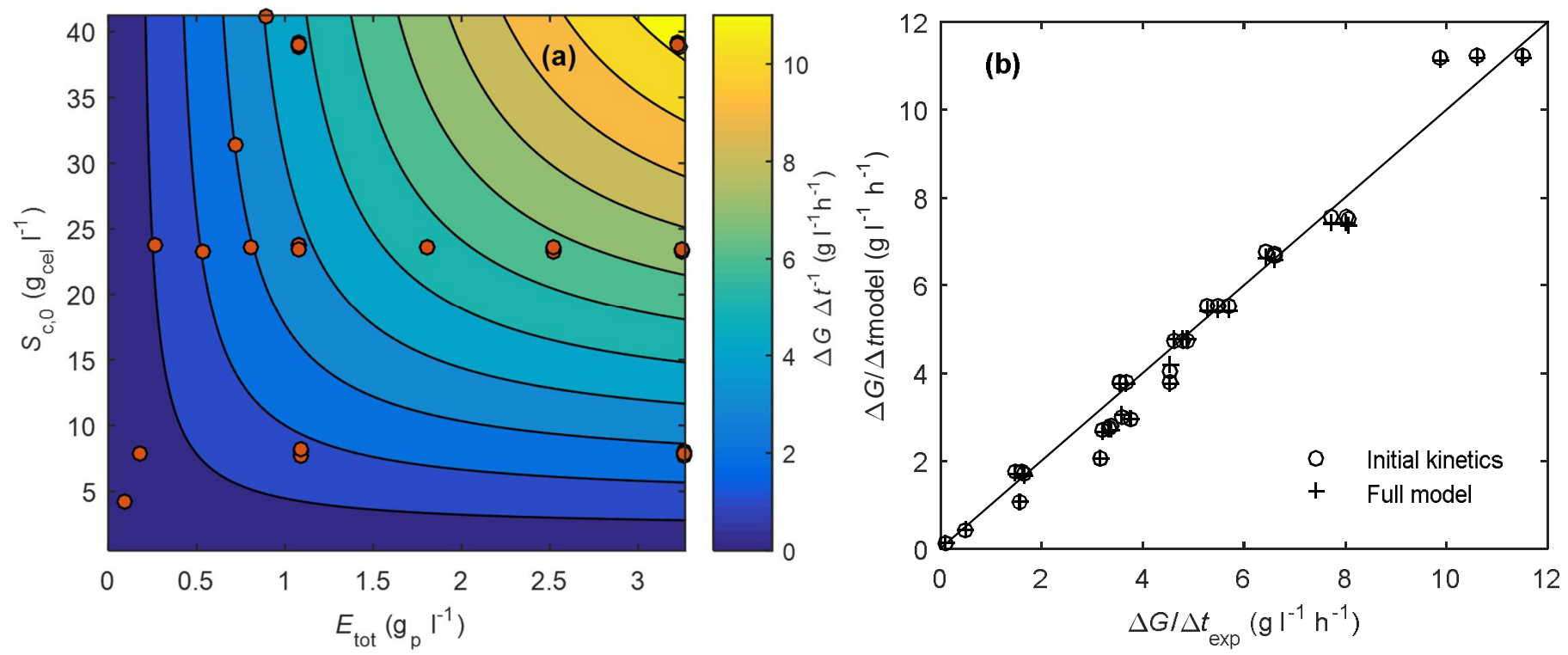

Figure 1. Initial kinetic model. (a): Conto ur plot of model-estimated average glucose release rate during the first 30 minutes as a function of total enzyme concentration ( $\left.E_{t o t}\right)$ and initial cellulose concentration $\left(S_{c, 0}\right)(\mathbf{b})$ : Parity plot of the model-estimated initial glucose release rate vs. the measured rate. The values calculated with the full model are also shown in the plot. 

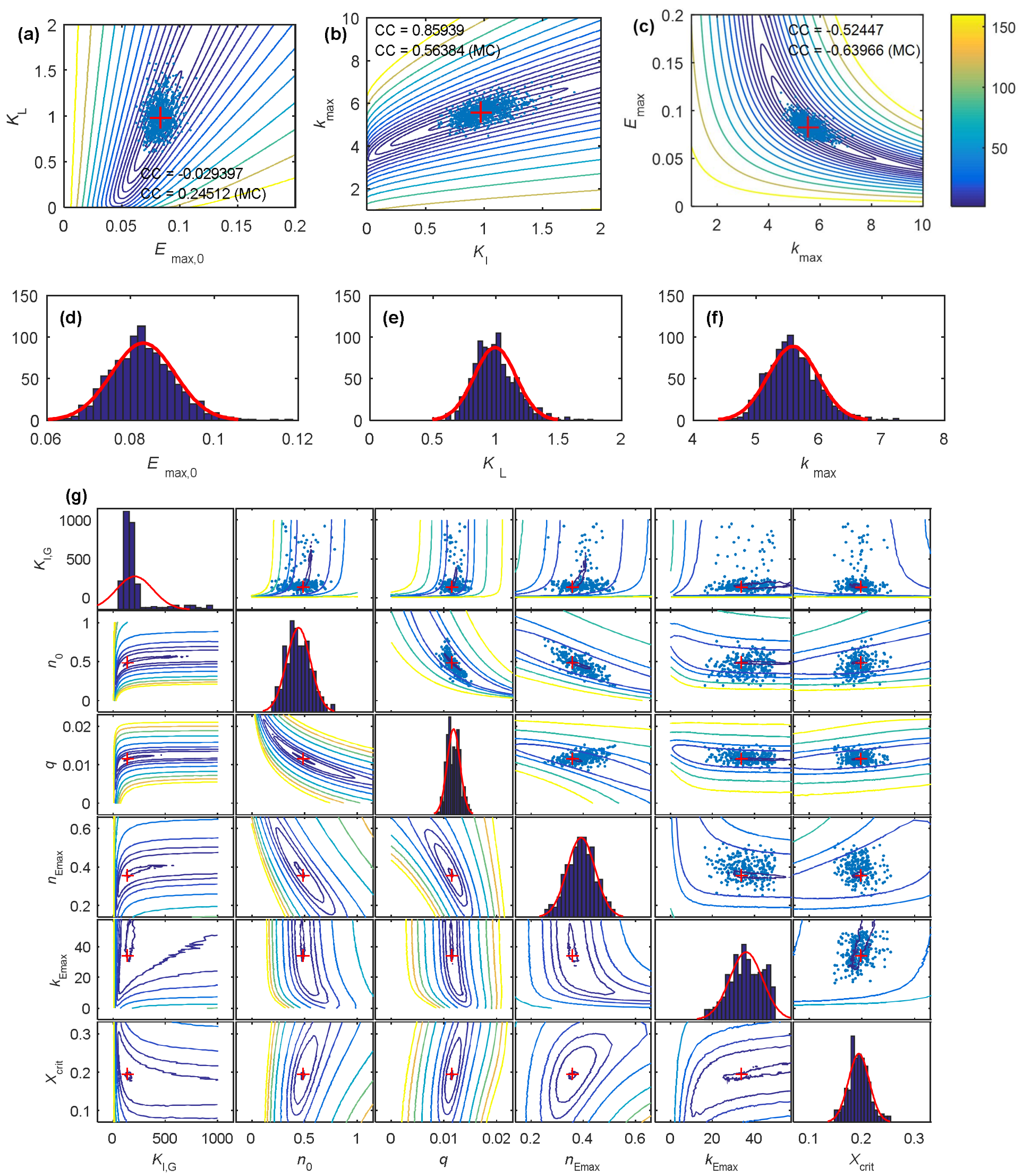

Figure 2. Parameter sensitivity studies for initial kinetic parameters (af) and full model parameters (g). Contour plot of the objective function value for the parameter-pairs, and the estimated parameter values from the M onte Carlo simulations ( $n=1000$ for initial kinetic model (ac) and $n=270$ for the full model (g)). Histogram plots of M onte Carlo simulations are given for each parameter in the initial kinetic model (d-f) and full model (g). Correlation coefficients (CC) are calculated from the mo del sensitivity analysis for the initial kinetic model (see Supplementary material) and the M onte Carlo simulations (M C). 

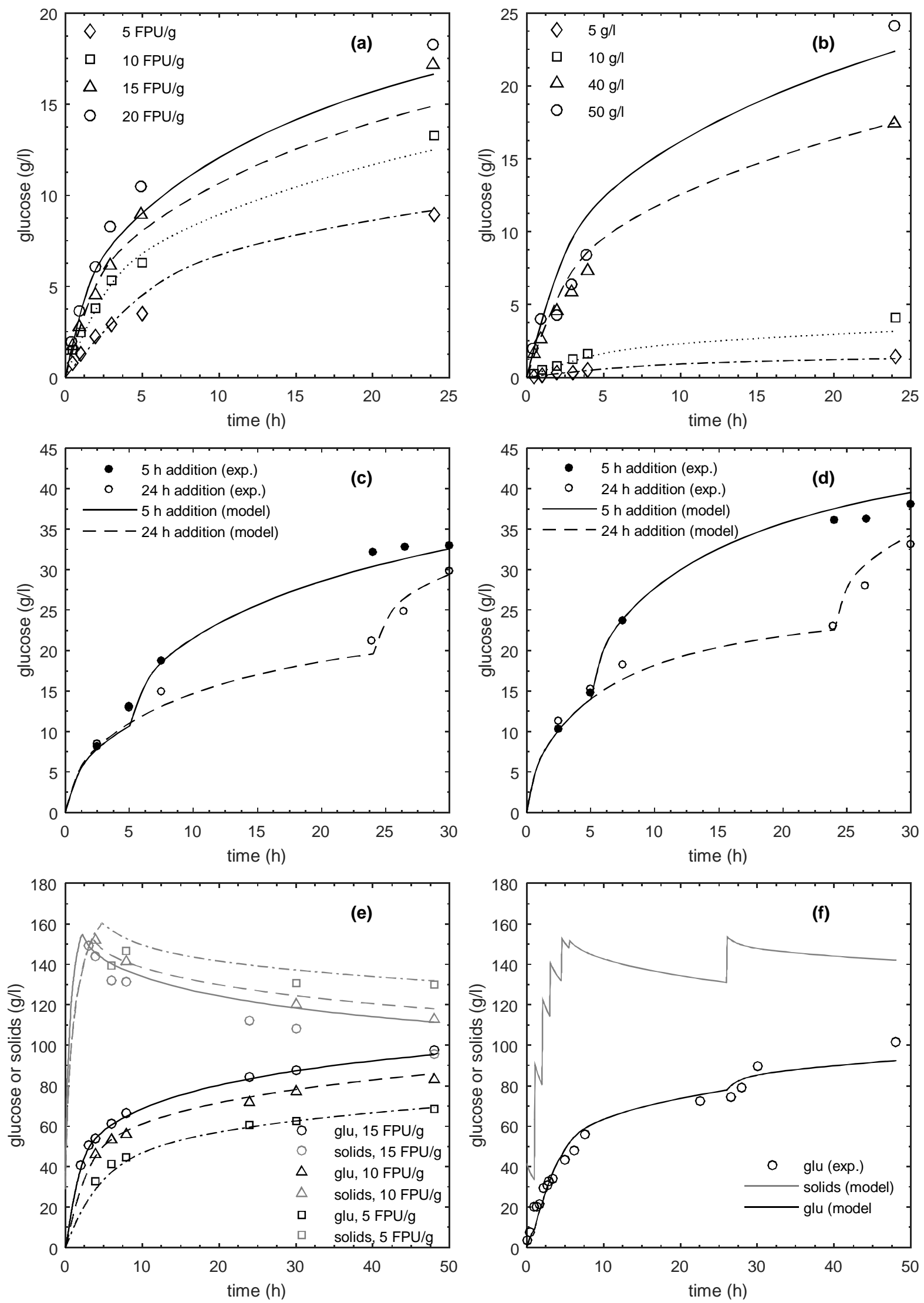

Figure 3. Experimental and model-estimated glucose concentrations during the hydrolysis experiments. (a-b): Small scale batch experiments with varying enzyme dosage and constant initial solids concentration $\mathbf{( 3 0} \mathbf{g} / \mathbf{l}, \mathbf{a})$ and varying initial solids concentration and constant enzyme dosage (10 $\mathbf{F U / g} \mathbf{~ b ) ~ ( c - d ) : ~ S m a l l ~ s c a l e ~ f e d - b a t c h ~ e x p e r i m e n t s ~ w i t h ~ o n e ~ s u b s t r a t e ~ a d d i t i o n . ~ I n i t i a l ~ s o ~ l i d s ~ c o n c e n t r a t i o n ~ i s ~} 30 \mathrm{~g} / \mathrm{l}$, and addition to $60 \mathrm{~g} / \mathrm{l}$ at $5 \mathrm{~h}$ or $24 \mathrm{~h}$. Enzyme dosage per total added solids is $15 \mathrm{FPU} / \mathrm{g}$ (c) and $30 \mathrm{FPU} / \mathrm{g}$ (d), (e-f): M easured and model-estimated glucose and solids concentration during fed-batch experiments with constant stirring power during the feeding phase and total amount of added solids $200 \mathrm{~g} / \mathrm{l}$ (e) and with pulsed feeding in reactor with enzyme dosage is $8 \mathrm{FPU} / \mathrm{g}$, the total added solids $235 \mathrm{~g} / \mathrm{l}$ with a late addition (26 h) of the last pulse $(30 \mathrm{~g}) \mathbf{( f )}$ 


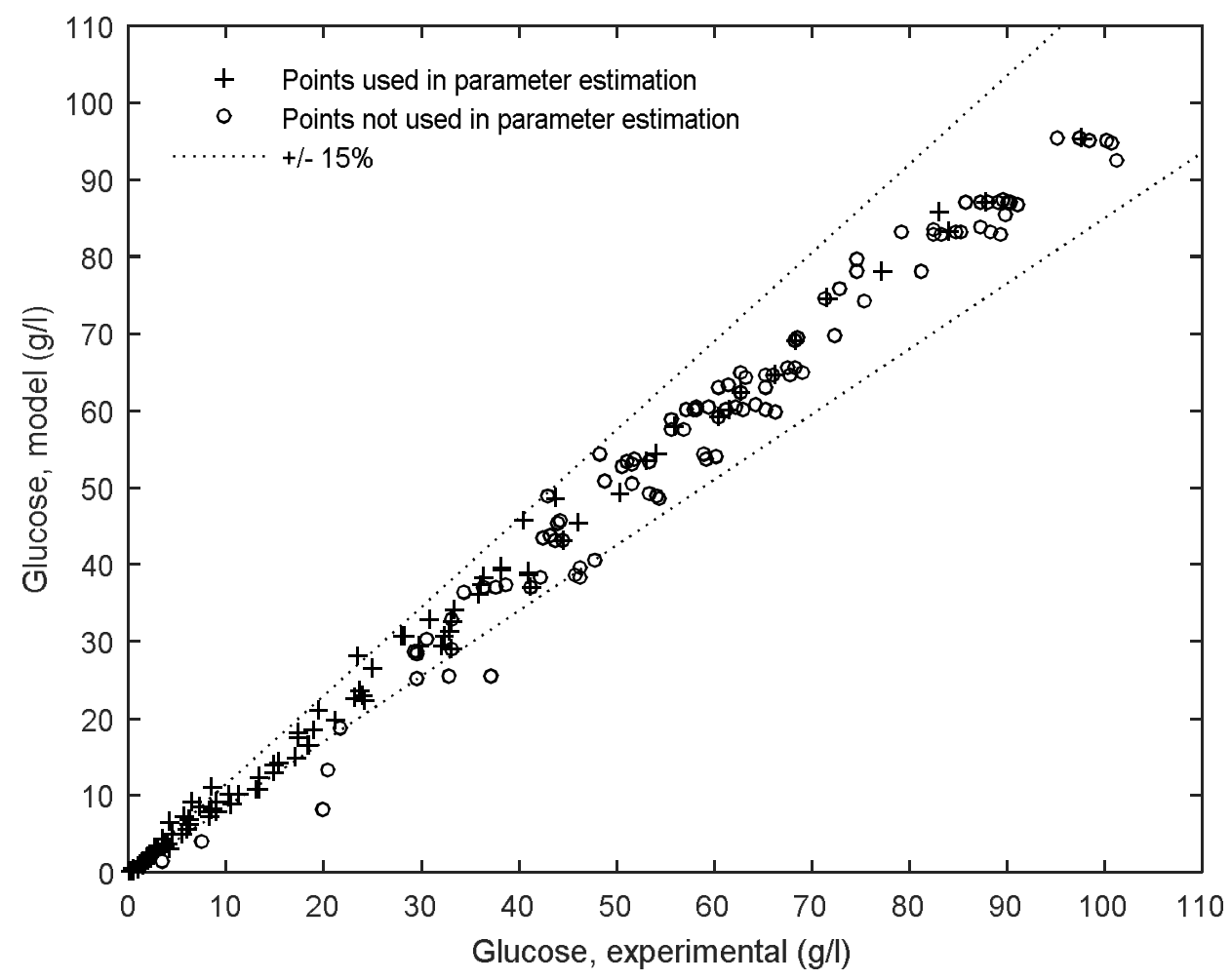

Figure 4. Parity plot of the measured and model-estimated liquid phase glucose concentrations of all measurement points (a total of 31 experiments and 204 measurements, $R^{2}=0.99$ ) 


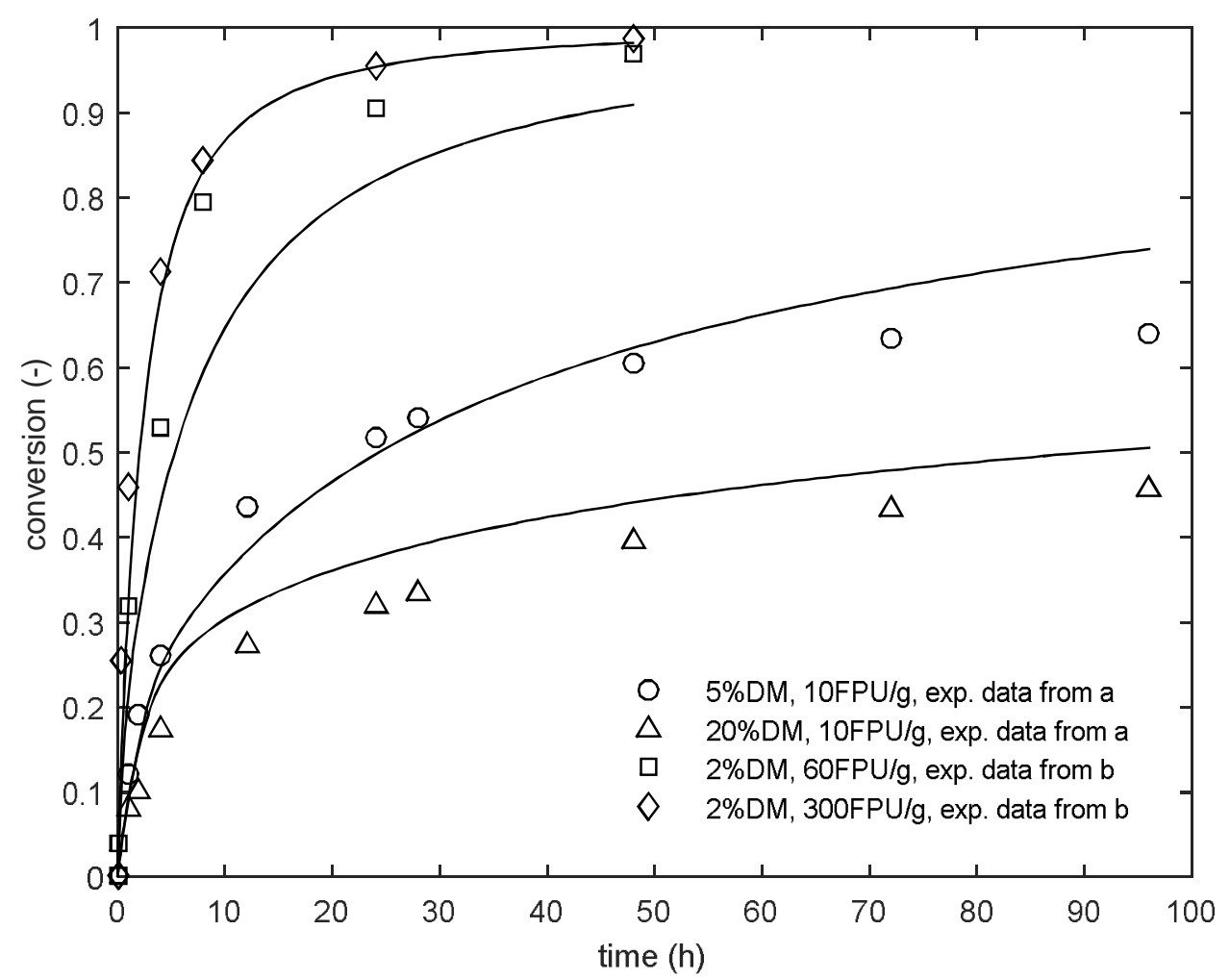

Figure 5. Comparison of the model predictions with literature data, (a) (Kristensen et al., 2009), (b) (Boussaid and Saddler, 1999) 

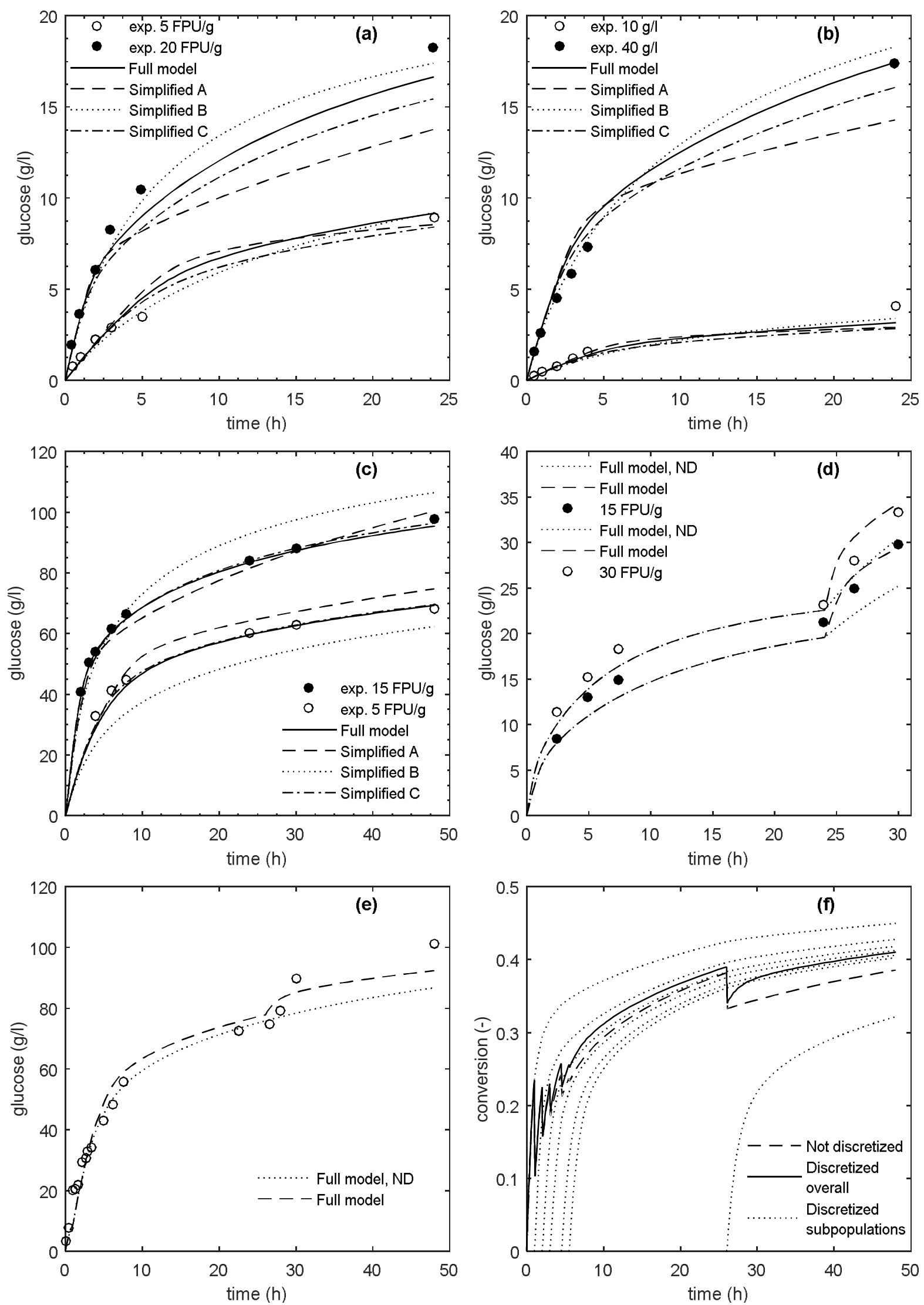

Figure 6. Comparison of simplified (a-c) and not discretized (d-f) versions of the mode with the full model. Simplified models A, B and C in batch hydrolysis with constant solids concentration $(\mathbf{3 0} \mathbf{g} / \mathbf{l}, \mathbf{a})$ and constant enzyme do sage $(\mathbf{1 0} \mathbf{F U} / \mathbf{g} \mathbf{~ b})$ and in fed-batch experiments with constant stirring power during substrate feeding (c). Full model and not discretized model (ND) in fed-batch hydrolysis in small scale (d) and in reactor scale with pulsed feeding and late substrate addition, glucose vs. time (e) and conversion vs. time (f) 